\title{
Carbonation Characteristics of Alkali-Activated Blast-Furnace Slag Mortar
}

\author{
Keum-Il Song, ${ }^{1}$ Jin-Kyu Song, ${ }^{1}$ Bang Yeon Lee, ${ }^{1}$ and Keun-Hyeok Yang ${ }^{2}$ \\ ${ }^{1}$ School of Architecture, Chonnam National University, Gwangju 500-757, Republic of Korea \\ ${ }^{2}$ Department of Plant Architectural Engineering, Kyonggi University, Suwon-si, Gyeonggi-do 443-760, Republic of Korea \\ Correspondence should be addressed to Jin-Kyu Song; jgsong@jnu.ac.kr
}

Received 13 May 2014; Accepted 14 July 2014; Published 7 August 2014

Academic Editor: Bin Li

Copyright (c) 2014 Keum-Il Song et al. This is an open access article distributed under the Creative Commons Attribution License, which permits unrestricted use, distribution, and reproduction in any medium, provided the original work is properly cited.

\begin{abstract}
Alkali-activated ground granulated blast-slag (AAS) is the most obvious alternative material for ordinary Portland cement (OPC). However, to use it as a structural material requires the assessment and verification of its durability. The most important factor for a durability evaluation is the degree of carbonation resistance, and AAS is known to show lower performance than OPC. A series of experiments was conducted with a view to investigate the carbonation characteristics of AAS binder. As a consequence, it was found that the major hydration product of AAS was calcium silicate hydrate (CSH), with almost no portlandite, unlike the products of OPC. After carbonation, the CSH of AAS turned into amorphous silica gel which was most likely why the compressive strength of AAS became weaker after carbonation. An increase of the activator dosage leads AAS to react more quickly and produce more $\mathrm{CSH}$, increasing the compaction, compressive strength, and carbonation resistance of the microstructure.
\end{abstract}

\section{Introduction}

Environmental pollution, global warming, and resource exhaustion are very serious issues worldwide. The cement industry is considered to be one of the significant contributors to these issues because carbon dioxide $\left(\mathrm{CO}_{2}\right)$ comprises $82 \%$ of the total greenhouse gases (GHGs) emitted by humans [1] and the $\mathrm{CO}_{2}$ produced from the cement industry is as high as $7 \%$ of the global anthropogenic $\mathrm{CO}_{2}$ production [2]. Furthermore, it is well known that the construction industry consumes significant amounts of minerals and produces industrial waste [3]. Various approaches to reducing $\mathrm{CO}_{2}$ from cement production have been investigated and some adopted, such as the reduction of $\mathrm{CO}_{2}$ emissions during cement production, a reduction of energy consumption during clinker production, and a reduction of the clinker content in cement [1]. Since the 1960s, many studies have been carried out seeking to replace some of the ordinary Portland cement (OPC) of concrete with industrial by-products, such as ground granulated blast furnace slag (hereafter, GGBS) or fly ash, and to develop cementless alkali-activated types of concrete to improve the sustainability in the construction industry [4-7].
Alkali-activated slag (AAS) binders have no clinker, a source material (S.M) of cement, thus enabling a significant reduction of carbon dioxide emission in the manufacturing process. The use of such by-products can also resolve the problem of disposing of industrial waste. The physical performance of AAS binders generally satisfies or surpasses that of cement [8-11], showing higher chemical resistance [12, 13] and earlier age strength development than cement [14]. However, the durability of AAS-based concrete significantly depends on the types and amounts of activators added [15]. In particular, a recent study showed that it has a lower carbonation resistance than that of OPC $[16,17]$. The carbonation rate of an alkali-activated slag concrete with a water-to-slag ratio of 0.35 was similar to that of Portland cement concrete with a water-to-cement ratio of 0.60 [18].

The aim of this study is to investigate the carbonation characteristics of AAS binder. For this purpose, mortar specimens of AAS with different dosages of activator and OPC were made to evaluate the changes between their physical properties and identify hydration products before and after carbonation through tests of the flow, compressive strength, and carbonation depth measurement, which together with 
TABLE 1: Chemical compositions of the source materials and alkali activators used (\% by mass).

\begin{tabular}{lcccccccccc}
\hline Materials & $\mathrm{SiO}_{2}$ & $\mathrm{Al}_{2} \mathrm{O}_{3}$ & $\mathrm{Fe}_{2} \mathrm{O}_{3}$ & $\mathrm{CaO}$ & $\mathrm{MgO}$ & $\mathrm{K}_{2} \mathrm{O}$ & $\mathrm{Na}_{2} \mathrm{O}$ & $\mathrm{TiO}_{2}$ & $\mathrm{SO}_{3}$ & $\begin{array}{c}\mathrm{Blaine} \mathrm{fineness}^{2} \\
\left(\mathrm{~m}^{2} / \mathrm{kg}\right)\end{array}$ \\
\hline OPC & 20.9 & 5.39 & 2.38 & 64.7 & 1.51 & 0.22 & 0.27 & 1.33 & 1.65 & 301 \\
GGBS & 33.58 & 12.70 & 0.31 & 42.09 & 4.62 & 0.35 & 0.20 & 0.62 & 4.83 & 430 \\
\hline
\end{tabular}

TABLE 2: Mix proportions.

\begin{tabular}{|c|c|c|c|c|c|c|c|}
\hline \multirow{2}{*}{ Mix } & \multicolumn{4}{|c|}{ Binder } & \multirow{2}{*}{$\mathrm{Na}_{2} \mathrm{O} / \mathrm{S} \cdot \mathrm{M}^{\mathrm{a}}$} & \multirow{2}{*}{$\mathrm{W} / \mathrm{B}^{\mathrm{b}}$} & \multirow{2}{*}{$\mathrm{S} / \mathrm{B}^{\mathrm{c}}$} \\
\hline & Source material & wt $\%$ & Activator & wt $\%$ & & & \\
\hline OPC & OPC & 100 & - & - & - & \multirow{4}{*}{0.485} & \multirow{4}{*}{2.75} \\
\hline G3 & \multirow{3}{*}{ GGBS } & 94 & \multirow{3}{*}{$\mathrm{Na}_{2} \mathrm{SiO}_{3}$} & 6 & 0.03 & & \\
\hline G5 & & 90 & & 10 & 0.05 & & \\
\hline G7 & & 86 & & 14 & 0.07 & & \\
\hline
\end{tabular}

${ }^{\mathrm{a}} \mathrm{S} . \mathrm{M}$ : source material.

${ }^{\mathrm{b}} \mathrm{W} / \mathrm{B}$ : water-to-binder ratio by weight.

${ }^{\mathrm{c}} \mathrm{S} / \mathrm{B}$ : sand-to-binder ratio by weight.

X-ray powder diffraction (XRD), Fourier-transform nearinfrared spectroscopy (FT-NIR), a derivative thermal gravimetric analysis (DTG), and environmental scanning electron microscopy (ESEM) were used for an assessment.

\section{Experimental Program}

2.1. Materials. Type I Portland cement (OPC) and ground granulated blast-slag (GGBS) satisfying the ACI SP-114 specification were used as the binders in all mixtures. Table 1 shows the chemical composition and Blaine fineness of the OPC and GGBS. The chemical composition was characterized by X-ray fluorescence (XRF) spectrometry using an Axios Minerals instrument. Their fineness was determined with an air permeability apparatus according to ASTM C204. The Blaine fineness of the GGBS was $430 \mathrm{~m}^{2} / \mathrm{kg}$ and the maximum and average particle size of the GGBS used in this study were $76.3 \mu \mathrm{m}$ and $8.5 \mu \mathrm{m}$, respectively. The specific gravity and the alkalinity of the GGBS were 2.93 and 1.81, respectively. Alkali activators can be classified [19] into caustic alkalis with hydroxide, nonsilicate weak-acid salts, silicates, aluminates, aluminosilicates, and nonsilicate strongacid salts. This research utilized sodium silicate granules as the activator, as many researchers have studied it in this field. The density of the fine aggregates is $2.63 \mathrm{~g} / \mathrm{cm}^{3}$; the effective granular diameters D10, D30, D50, and D60 are $0.331 \mathrm{~mm}$, $0.480 \mathrm{~mm}, 0.586 \mathrm{~mm}$, and $0.639 \mathrm{~mm}$, respectively; and the uniformity coefficient $(\mathrm{Cu})$ and the curvature coefficient $(\mathrm{Cc})$ are 1.93 and 1.09 .

2.2. Mixture Proportions. Two types of specimens were prepared. The mortar specimens are for measuring the compressive strength before and after carbonation and the carbonation depth. The paste specimens are for the XRD, FT-NIR, DTG, and ESEM analysis. The mixture proportions of the source materials are listed in Table 2. In the mortar, the weight ratios of water- and sand-to-binder were fixed at
0.485 and 2.75; no other admixtures were used. In the paste, the weight ratio of water-to-binder is 0.485 , identical to the mortar. The G3, G5, and G7 specimens of the AAS mortar and the paste were mixed by adding 6,10 , and $14 \%$ of the activator to the binder by weight; that is, 3,5 , and $7 \%$ of $\mathrm{Na}_{2} \mathrm{O}$ were added to the binder by weight, respectively.

\subsection{Mixing, Casting, and Curing of Specimens}

2.3.1. Mortar. Each of the four compositions described above was mixed in a Hobart planetary mixer. Solid ingredients, including binder, and sand were added to the mixer and mixed for approximately $3 \mathrm{~min}$. Water was slowly added and the mixture was then mixed for another $3 \mathrm{~min}$. After measuring the initial flow of each mixture, each mixture was cast into molds while moderate vibration was applied. The specimens for carbonation and noncarbonation mortar were cured by being sealed in order to prevent being exposed to the atmosphere for seven days of the initial curing. The molds filled with mortar were covered with plastic sheets (sealed curing) and cured in air at a constant temperature and relative humidity of $20 \pm 0.5^{\circ} \mathrm{C}$ and $70 \pm 2 \%$ for seven days. Demolded after seven days from casting, the specimens for noncarbonation were cured under the same conditions used before until testing. The specimens for carbonation were exposed to carbon dioxide gas in an accelerated carbonation chamber with a carbon dioxide concentration of $5.0 \pm 0.5 \%$ after demolding (Figure 1(a)).

2.3.2. Paste. The specimens were prepared in the same manner as the mortar except for the addition of sand and without measuring the initial flow. Both specimens for carbonation and noncarbonation were cured in sealed molds at a constant temperature and relative humidity of $20 \pm 0.5^{\circ} \mathrm{C}$ and $70 \pm 2 \%$, respectively, for seven days after mixing.

The specimens for carbonation were pulverized after demolding and then exposed to carbon dioxide gas under the same condition used with the carbonation mortar specimen. 


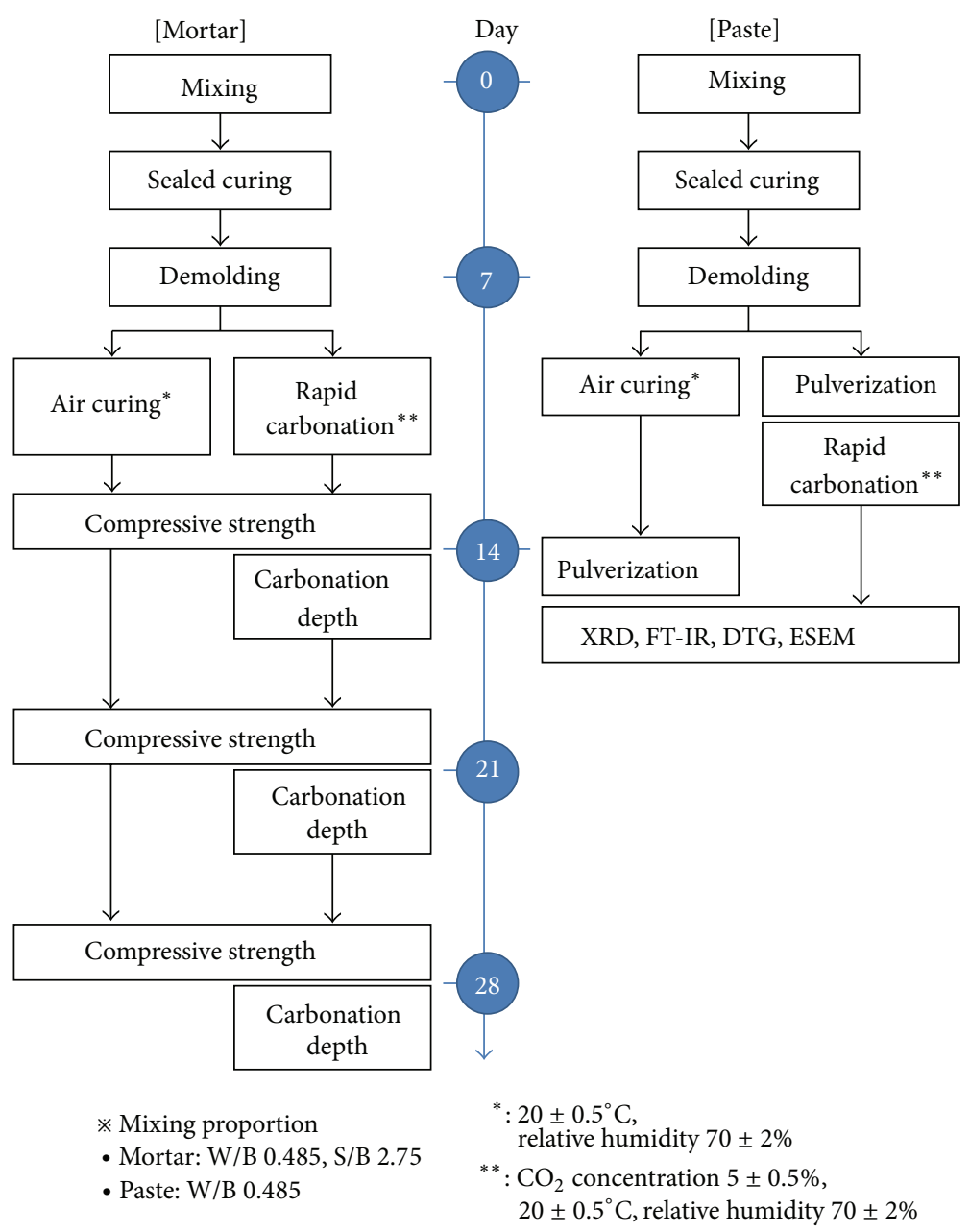

(a) Mortar

(b) Paste

FIGURE 1: Experimental program.

The specimens for noncarbonation were kept in a curing condition after demolding (Figure 1(b)).

\subsection{Experimental Method}

2.4.1. Anhydrous Slags and OPC. The chemical compositions of the anhydrous slag and OPC were analyzed by XRF using the Axios Minerals instrument. Powder X-ray diffraction (XRD) patterns were recorded on a PANalytical $X^{\prime}$ Pert Pro multipurpose X-ray diffractometer, $\theta-\theta$ geometry, equipped with $\mathrm{X}^{\prime}$ Celerator solid detector and using $\mathrm{CuK} \alpha$ radiation $(\lambda=1.54184 \AA)$. Powder patterns were recorded at room temperature at an interval of $5^{\circ}<2 \theta<60^{\circ}$ with a step size of $\Delta 2 \theta=0.01745^{\circ}$ and a counting time of 200 s per step. A total counting time of about $100 \mathrm{~min}$ was used for each sample.

2.4.2. Hydrated Mortars. The initial flow and compressive strength were tested and measured according to ASTM C109, and an accelerated carbonation test was carried out according to the method designed by Papadakis et al. [20]. During the test, the carbonation depth of each specimen was measured according to RILEM CPC-18 [21]. The carbonation specimens exposed for 7,14 , and 21 days in the accelerated carbonation chamber were measured to determine the carbonation depth and compressive strength in order to compare these values with those of noncarbonated specimens at equivalent ages of curing. A universal compressive strength testing machine with a constant load rate of $1 \mathrm{kN} / \mathrm{sec}$ and a $200 \mathrm{kN}$ capacity was used to measure the compressive strength of the $50 \times 50$ $\times 50 \mathrm{~mm}$ cubes.

2.4.3. Hydrated Paste. The paste samples for noncarbonation were cured under the same condition described above after demolding for seven days. The samples were then selected in an unexposed area of hardened paste and pulverized in clean bag of polyethylene (PE) film for XRD, FT-NIR, DTG, and ESEM at an age of 14 days.

The paste samples for carbonation, on the other hand, were pulverized after demolding at the age of seven days to obtain fully carbonated samples. The fragmented paste samples were then exposed to carbon dioxide gas in a rapid carbonation chamber for seven days. 
TABLE 3: Initial flow of the mortar mixes.

\begin{tabular}{lcccc}
\hline Mix & OPC & G3 & G5 & G7 \\
\hline Initial flow $(\mathrm{mm})$ & 170 & 185 & 195 & 190 \\
\hline
\end{tabular}

The samples for noncarbonation and carbonation were submerged in acetone to arrest hydration and prevent carbonation. The fragments used for XRD, FT-NIR, and DTG were ground to pass a $63 \mu \mathrm{m}$ sieve.

$\mathrm{XRD}$ was performed as described above with the same model.

FT-NIR analysis of the nanostructure of the materials obtained was conducted with a spectrum 400 device (PerkinElmer). The KBr pellet method (1.5 mg powder sample mixed with $150 \mathrm{mg}$ of $\mathrm{KBr}$ ) was used to prepare the samples, which were scanned at a range of 4000 to $400 \mathrm{~cm}^{-1}$. FT-NIR analysis was recorded after 256 scans at a resolution of $0.4 \mathrm{~cm}^{-1}$ [22].

TGA analyses were performed on a Setaram TG92 apparatus. The powdered sample (about $10-15 \mathrm{mg}$ ) was placed in an alumina crucible, and the measurements were made from room temperature up to $1,100^{\circ} \mathrm{C}$ at a heating rate of $10^{\circ} \mathrm{C} / \mathrm{min}$ under an air flow of $20 \mathrm{~mL} / \mathrm{min}$. A blank curve, obtained under the same conditions with the same empty alumina crucible, was systematically subtracted [23].

The Quanta 200 FEG environmental scanning electron microscope (ESEM) equipped with an energy dispersive Xray analyzer (EDX) was used to examine the microstructure before and after the carbonation of samples of OPC, G3, G5, and G7. This apparatus can scan a sample without preparation, such as drying.

\section{Results and Discussion}

3.1. Initial Flow. Table 3 presents the result of the mortar initial flow test. As shown in this table, AAS binders showed higher flow values than OPC. The G5 and G7 specimens with more added activator showed higher values than G3. This can be attributed to the ball-bearing effect, which occurred when the alkalis used as an activator are dissolved into water and absorbed in granules. The lowered flow value of G7 compared to that of G5 most likely occurred because the addition of an activator above a certain amount increased the reactivity of the binders and caused quick setting.

3.2. Carbonation Depth. Figure 2 shows the carbonation depth of each specimen. The carbonation depth of AAS mortar tended to be higher than that of OPC. After accelerated carbonation for seven days, the carbonation depth of the G3 mortar was 2.5 times higher than that of OPC. All specimens were fully carbonated before 14 days under an accelerated carbonation environment. However, the depth of carbonation decreased with an increase in the amount of activator added. For G7 after accelerated carbonation for seven days, its carbonation depth was lower than that of OPC, and, for 21 days, its carbonation depth was similar to that of OPC.

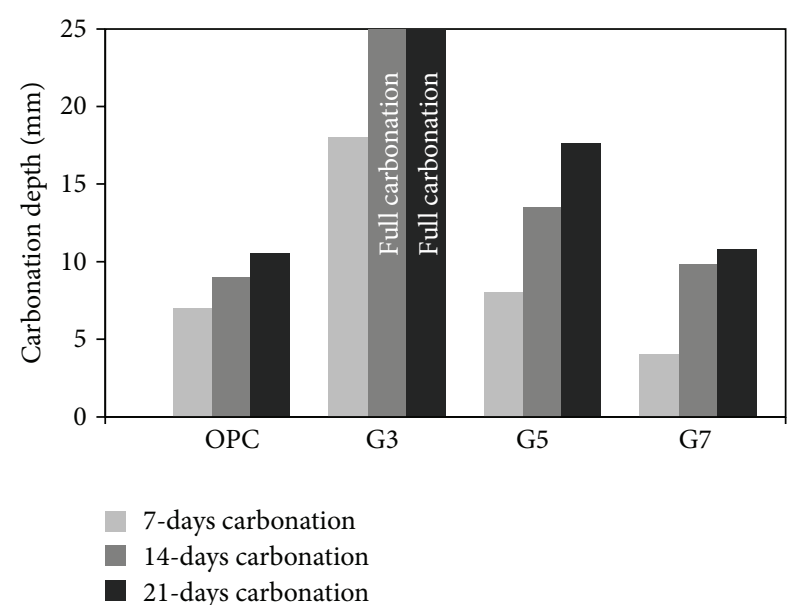

FIGURE 2: Carbonation depth of AAS mortar by accelerated carbonation.

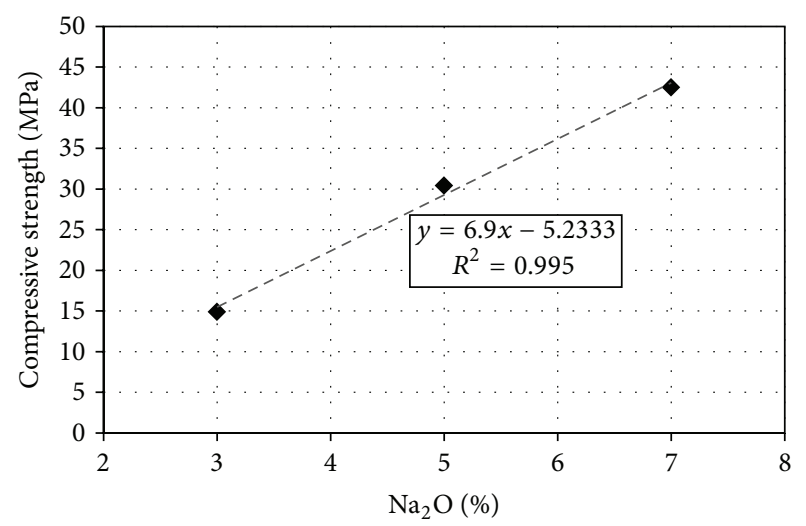

FIGURE 3: Relationship between $\mathrm{Na}_{2} \mathrm{O}$ and the compressive strength in AAS mortar.

3.3. Compressive Strength. Table 4 depicts the compressive strengths of the mortars before and after carbonation at 14,21 , and 28 days of curing. Test results showed that the strengths of the OPC and AAS mortars increased with age and that the compressive strengths of G5 and OPC were at similar levels. As indicated in Figure 3, the compressive strength of the AAS mortar increased as the amount of activator increased. Figure 4 shows the relationship between the compressive strength and carbonation depth in the AAS mortar. The compressive strength is the governing factor of carbonation resistance. Figure 5 shows the relative compressive strengths of the carbonated specimens, which is the ratio of the compressive strength of the carbonated and the noncarbonated specimens. After accelerated carbonation, the compressive strength of the OPC specimen increased. The compressive strengths of the specimens carbonated for three weeks were approximately 1.5 times higher than those of the noncarbonated specimens. In contrast, carbonated AAS mortars showed lower strengths than before carbonation for all specimens, and the loss of strength increased with the length of the accelerated carbonation period. It was also observed that the loss of strength decreased with an increase 
TABLE 4: Compressive strength of the mortar mixes (unit: MPa).

\begin{tabular}{|c|c|c|c|c|}
\hline \multirow{2}{*}{ Mix } & Condition & \multicolumn{3}{|c|}{ Compressive strength (MPa) } \\
\hline & $\begin{array}{c}\text { Age } \\
\text { carbonation period }\end{array}$ & $\begin{array}{l}14 \text { days } \\
7 \text { days }\end{array}$ & $\begin{array}{l}21 \text { days } \\
14 \text { days }\end{array}$ & $\begin{array}{l}28 \text { days } \\
21 \text { days }\end{array}$ \\
\hline \multirow{2}{*}{ OPC } & Noncarbonation & 23.5 & 28.4 & 32.1 \\
\hline & Carbonation & 29.4 & 38.3 & 45.1 \\
\hline \multirow{2}{*}{ G3 } & Noncarbonation & 12.5 & 13.1 & 14.9 \\
\hline & Carbonation & 7.5 & 7.2 & 7.6 \\
\hline \multirow{2}{*}{ G5 } & Noncarbonation & 26.4 & 28.1 & 30.4 \\
\hline & Carbonation & 22.0 & 19.5 & 16.7 \\
\hline \multirow{2}{*}{ G7 } & Noncarbonation & 36.7 & 39.6 & 42.5 \\
\hline & Carbonation & 33.7 & 32.0 & 28.9 \\
\hline
\end{tabular}

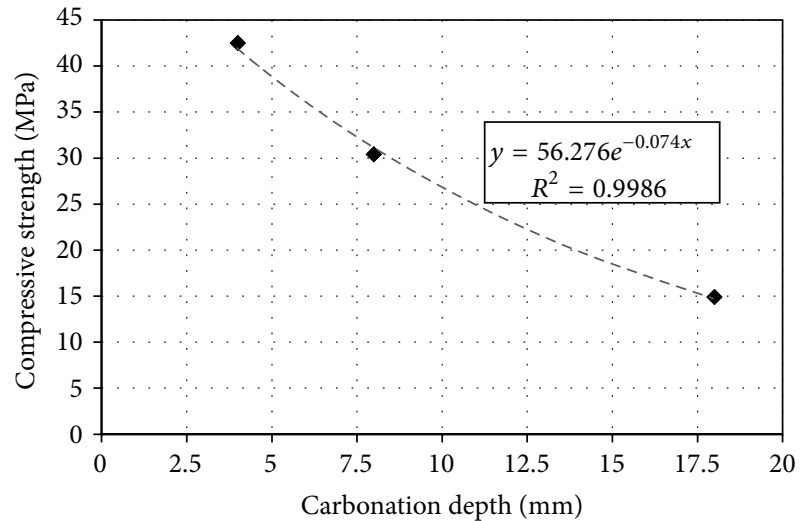

FIGURE 4: Relationship between the compressive strength and the carbonation depth with rapid carbonation for seven days in AAS mortar.

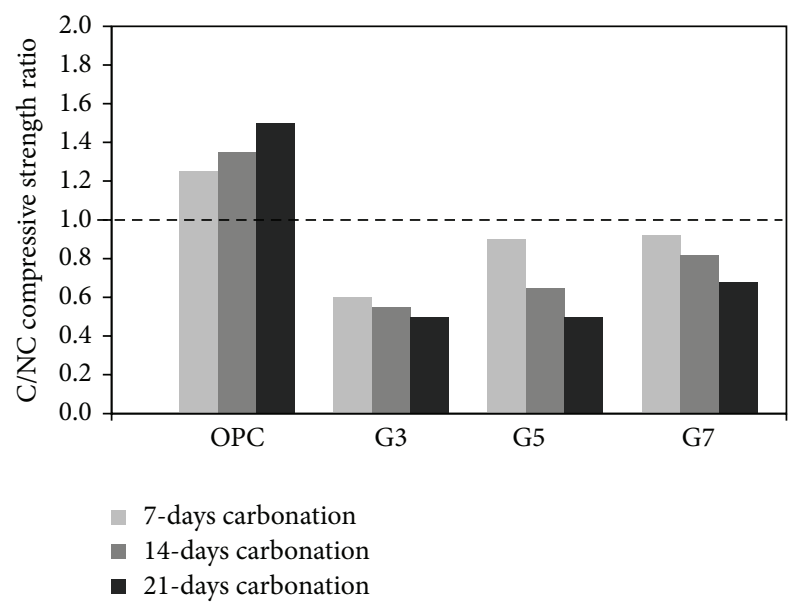

FIGURE 5: Ratio of the carbonation/noncarbonation (C/NC) compressive strength of the mortar.

in the amount of activator, which appears to be associated with the degree of carbonation, quantified as the depth of carbonation.

The carbonated and noncarbonated product areas of AAS mortars were measured to determine the loss rate of

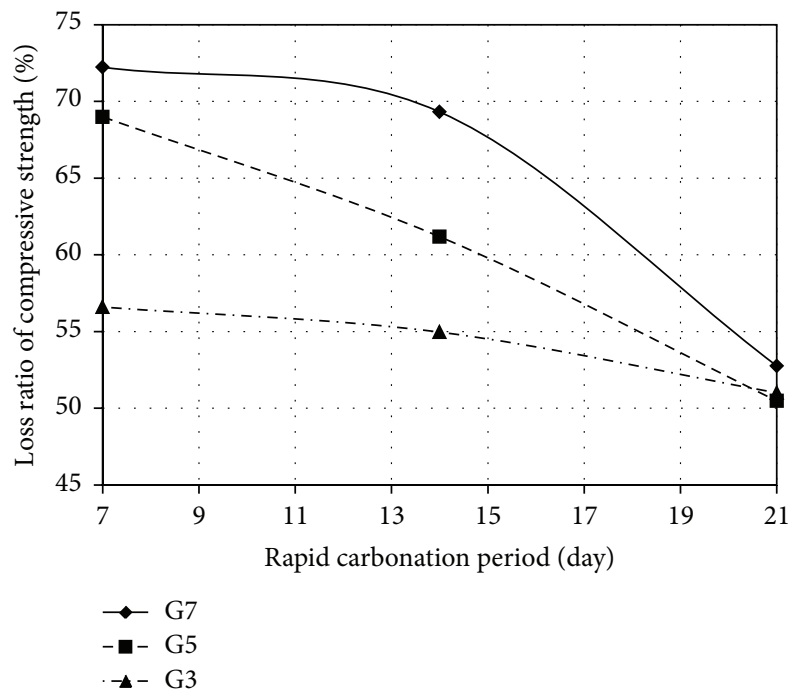

FIGURE 6: Compressive strength loss of the carbonation product in the AAS mortar.

the compressive strength of the carbonation product by the carbonation depth (Table 5). The compressive strength of the carbonated product in the AAS mortars was obtained by solving the proportional expression. Figure 6 shows the strength loss of the carbonated product. The strength of the carbonated product converged to approximately $50 \%$ of the noncarbonated product during the accelerated carbonation period in all AAS samples. From this observation, it was verified that the strength of the AAS mortar decreases as the degree of carbonation increases, in contrast to OPC.

3.4. Powder X-Ray Diffraction (XRD). Figure 7 shows the XRD diffraction patterns of carbonated and noncarbonated OPC paste. It was observed that as carbonation progressed, the portlandite $\left(\mathrm{Ca}(\mathrm{OH})_{2}\right)$ proportion was significantly reduced after carbonation, whereas at the same time calcites $\left(\mathrm{CaCO}_{3}\right)$ are generated. The amounts of ettringite $\left(\mathrm{Ca}_{6} \mathrm{Al}_{2}\left(\mathrm{SO}_{4}\right)_{3}(\mathrm{OH})_{12} \cdot 26 \mathrm{H}_{2} \mathrm{O}\right)$ and calcium silicate $\left(\mathrm{Ca}_{2} \mathrm{SiO}_{5}\right)$ also decreased. It is a well-known fact that the exact identification of the existence and amounts of $\mathrm{CSH}$ 


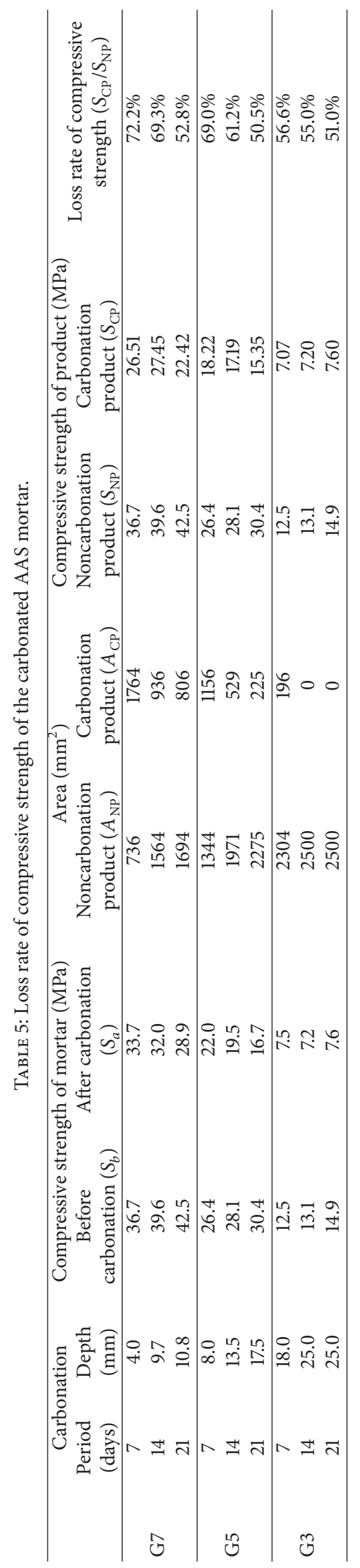




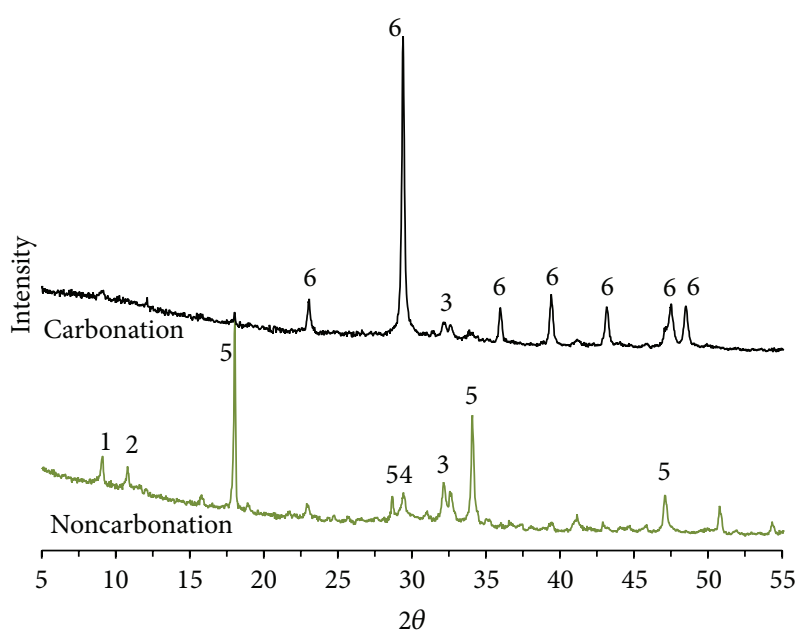
(1) Ettringite
(4) $\mathrm{CSH}$
(2) Gypsum
(3) Calcium silicate
(5) Portlandite $\left(\mathrm{Ca}(\mathrm{OH})_{2}\right)$
(6) Calcite $\left(\mathrm{CaCO}_{3}\right)$

FIGURE 7: XRD diffraction patterns of carbonated and noncarbonated OPC mortar.

through an XRD analysis is difficult, as CSH has a semicrystalline form in a natural state. Although a peak around $29^{\circ} \mathrm{C}$ may be associated with the existence of CSH, it is impossible to determine the increase or decrease of CSH by carbonation only through the result of an XRD analysis, as the increase of the $29^{\circ} \mathrm{C}$ peak after carbonation is associated with the increase of calcite as well.

Figure 8 shows the XRD diffraction patterns of carbonated and noncarbonated AAS paste. It can be observed that the amount of calcite in noncarbonated AAS paste is larger than that in noncarbonated OPC and that the AAS paste before carbonation included albite ((Na, Ca) $\mathrm{Al}(\mathrm{Si}$, $\mathrm{Al})_{3} \mathrm{O}_{8}$ ), sodium aluminum silica, calcite, quartz, and $\mathrm{CSH}$. It was also noted that an increase in amount of additional activator led to an increase of quartz among the hydration products of AAS; this appeared to be associated with the amounts of $\mathrm{Na}^{+}$and $\mathrm{SiO}_{4}{ }^{2-}$ in the sodium silicate used as activator. After carbonation, the calcite increased in the AAS paste. Meanwhile, albite and sodium aluminium silica completely disappeared upon carbonation. The generation of albite is determined to have been caused by $\mathrm{Ca}^{+}$due to the compositional structure and thus is not significantly changed by the addition of sodium silicate. In the AAS paste after hydration, aluminum-containing hydrates were discovered, but all of them disappeared after carbonation. Among the hydration products of AAS, therefore, aluminum compounds seem to be highly vulnerable to carbonation.

\subsection{Fourier-Transform Near-Infrared Spectroscopy (FT-NIR).} Figure 9 shows the result of infrared spectroscopy on the OPC specimens before and after carbonation. A vibration band was observed at $3,643 \mathrm{~cm}^{-1}$, corresponding to the $\mathrm{O}-\mathrm{H}$ bond in portlandite, but it disappeared after carbonation. As a result of the carbonation process, vibration peaks of calcite appeared at 1436,877 , and $718 \mathrm{~cm}^{-1}$; it had appeared insignificantly at those regions before carbonation but became very high after carbonation. The asymmetric stretching vibration representing the $\mathrm{Si}-\mathrm{O}$ bond characteristic of the silicon tetrahedral $\left(\mathrm{SiO}_{4}\right)$ in the chain structure of CSH shifted from 969-979 to 1014-1022 $\mathrm{cm}^{-1}$ after carbonation, indicating the decomposition of CSH by carbonation and a higher degree of polymerization and lengthening of silicates within the remaining gel. That is, the carbonation of $\mathrm{CSH}$ makes the structure of silica gel amorphous such that this band shift signifies the existence of CSH before carbonation [24, 25].

Figures 10(a) and 10(b) demonstrate the results of infrared spectroscopy on the AAS binders before and after carbonation. The band at $1132-1138 \mathrm{~cm}^{-1}$ is due to the formation of amorphous silica gel by carbonation, indicating the existence of CSH before carbonation in AAS as in OPC. This silica gel is more amorphous than that of OPC $\left(1015 \mathrm{~cm}^{-1}\right)$, which indicates that the CSH structure of AAS differs from that of OPC. The amount of calcite in the carbonated AAS mortar (1432$1442,877-881$, and $720-722 \mathrm{~cm}^{-1}$ ) increased with an increase in the amount of alkaline activator, which is consistent with the results of the carbonation depth measurement and $\mathrm{X}$ ray diffraction results, also indicating that an increase in the activator amount leads to a higher amount of $\mathrm{CSH}$ and slower rate of carbonation in the microstructure. The band at $452-$ $458 \mathrm{~cm}^{-1}$ is associated with the rotation of the $\mathrm{O}-\mathrm{Si}-\mathrm{O}$ bond and was not changed significantly by carbonation [26, 27]. Moreover, as in OPC, the band at $1654-1658 \mathrm{~cm}^{-1}$ associated with the $\mathrm{H}-\mathrm{OH}$ bond of a water molecule can be identified.

\subsection{Derivative Thermal Gravimetric Analysis (DTG).} Figure 11 shows a DTG graph of OPC before and after carbonation. The peak around $430-480^{\circ} \mathrm{C}$ indicates the weight loss of portlandite by dehydration, and the higher peak of the noncar-bonated specimen compared to the carbonated specimen signifies a higher amount of portlandite. The weight loss around $500-650^{\circ} \mathrm{C}$ is due to the dehydration of chemically bound water from the silica gel, which is generated by the carbonation of CSH. The broader peak range of silica gel after carbonation than before indicates that $\mathrm{CSH}$ was changed into silica gel of the semicrystalline, unstable bond structure form by carbonation. The peak at $670-780^{\circ} \mathrm{C}$ indicates the weight loss of calcite decomposed by carbon dioxide. From the DTG result of OPC before and after carbonation, it was confirmed that the amounts of portlandite and CSH decreased by carbonation, which led to an increase in the amount of calcite and silica gel [28].

Figures 12(a) and 12(b) show DTG graphs of AAS before and after carbonation, respectively. For noncarbonated AAS specimens, most of the weight loss occurred between 200 and $400^{\circ} \mathrm{C}$, where $\mathrm{CSH}$ is dehydrated, and between 400 and $600^{\circ} \mathrm{C}$, where silica gel is dehydrated. It was observed that the temperature bandwidth of the weight loss in the silica gel (the $400-600^{\circ} \mathrm{C}$ peak) decreased with the addition of the activator in noncarbonated samples. However, the loss of weight in this temperature bandwidth increased with an increase in the activator added after carbonation. The intensity of the $400-600^{\circ} \mathrm{C}$ peak where silica gel is dehydrated 


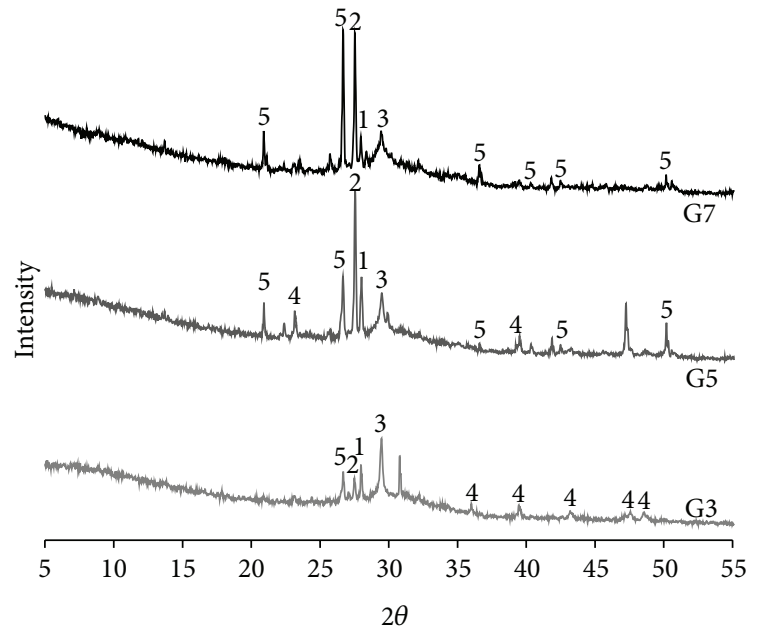
(1) Albite
(2) Sodium aluminium silica
(4) Calcite $\left(\mathrm{CaCO}_{3}\right)$
(3) $\mathrm{CSH}$
(5) Quartz $\left(\mathrm{SiO}_{2}\right)$

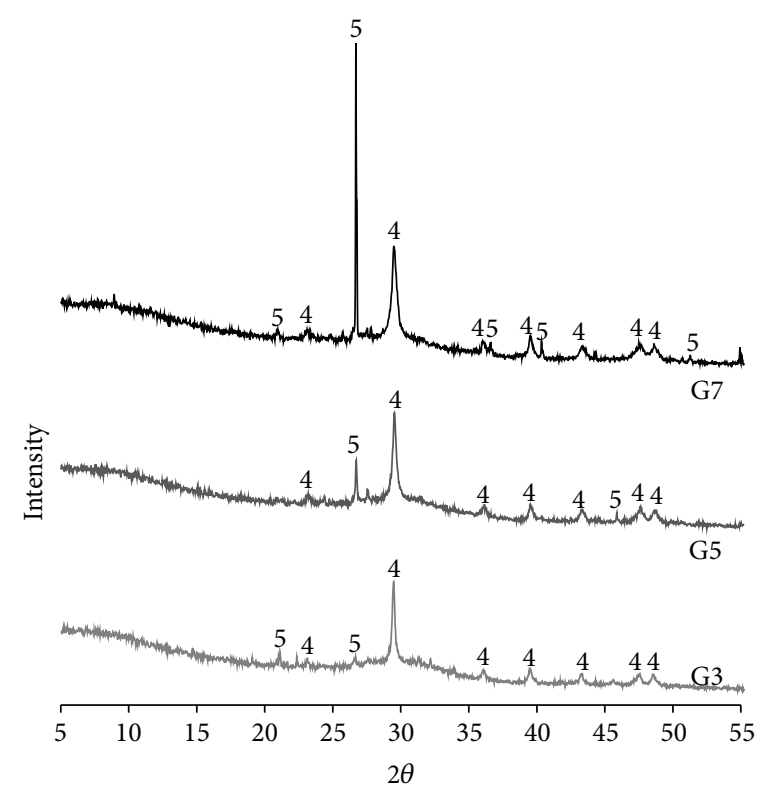

(1) Albite

(2) Sodium aluminium silica

(4) Calcite $\left(\mathrm{CaCO}_{3}\right)$

(3) $\mathrm{CSH}$
(5) Quartz $\left(\mathrm{SiO}_{2}\right)$

(b)

FIGURE 8: XRD diffraction patterns of noncarbonated (a) and carbonated (b) AAS mortar with different amounts of $\mathrm{Na}_{2} \mathrm{O} / \mathrm{S} . \mathrm{M}$.

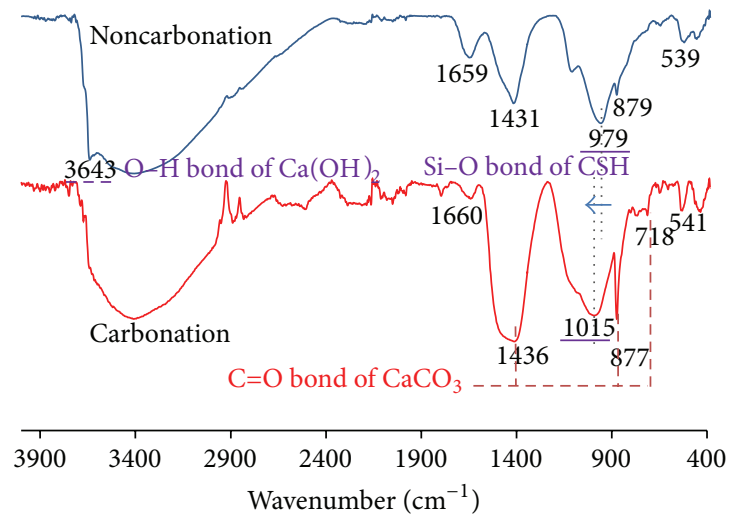

FIGURE 9: Fourier-transform infrared spectra of carbonated and noncarbonated OPC mortar.

indicates the amount of $\mathrm{CSH}$ before carbonation, as silica gel measured at this peak is the carbonation product of CSH. The peak of the carbonated G7 sample is the highest followed in order by G5 and G3 in this temperature bandwidth. All of these findings clarify that, by increasing the amount of the activating agent, the production of CSH is increased and the strength and carbonation resistance improve [28].

3.7. Scanning Electron Microscopy (SEM). Figure 13 shows images of OPC and AAS paste before and after carbonation taken by a scanning electron microscope. For hydrated OPC, these images show that the granules of the source material constitute a stratified structure and are bound with each other in amalgamation, leaving much ruggedness and porosity.
As carbonation progressed, however, many acicular materials were created in the porosity. These acicular structures entangle with each other and, by filling up the empty spaces, appear to lead to an increase in the strength of the OPC specimens after carbonation.

For AAS specimens, the more the alkaline activator is added, the more compact the structure becomes. This phenomenon can be explained in terms of the strength. That is, G3, whose compressive strength was determined as low, has no compact structure, as the slag granules could not be hydrated. In contrast, it was observed that adding a sufficient amount of activator leads to most of the slag granules being hydrated and assuming a compact microstructure. G7 showed small cracks in the microstructures of its hydration 


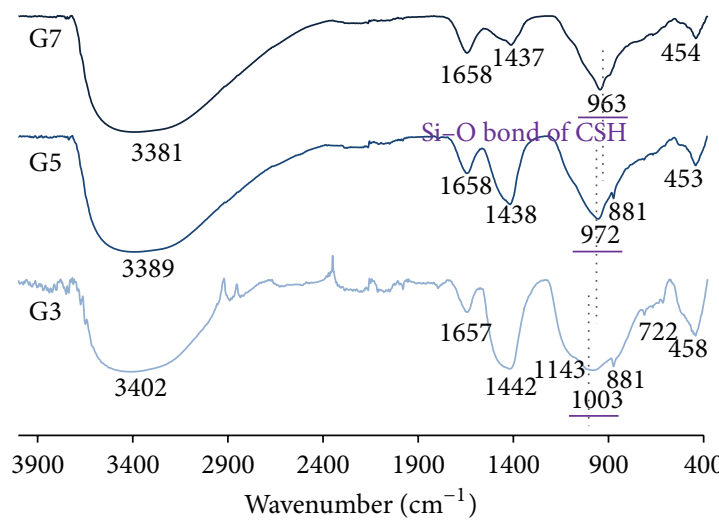

(a)

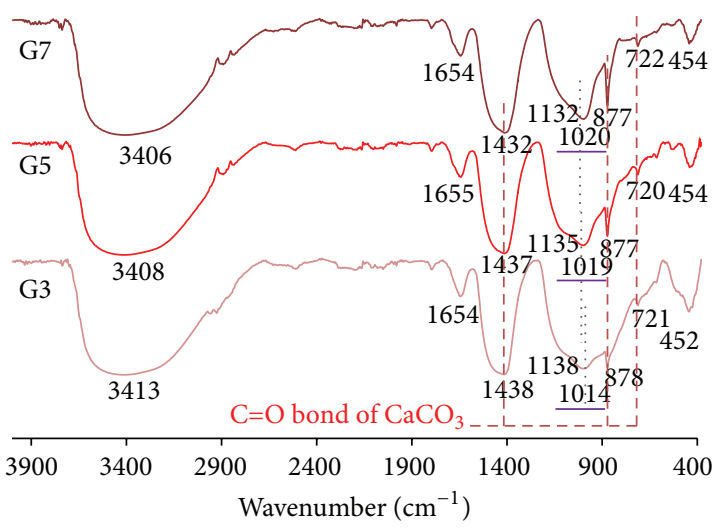

(b)

FIGURE 10: (a) Fourier-transform infrared spectra of noncarbonated AAS and (b) Fourier-transform infrared spectra of the carbonated AAS mortar.

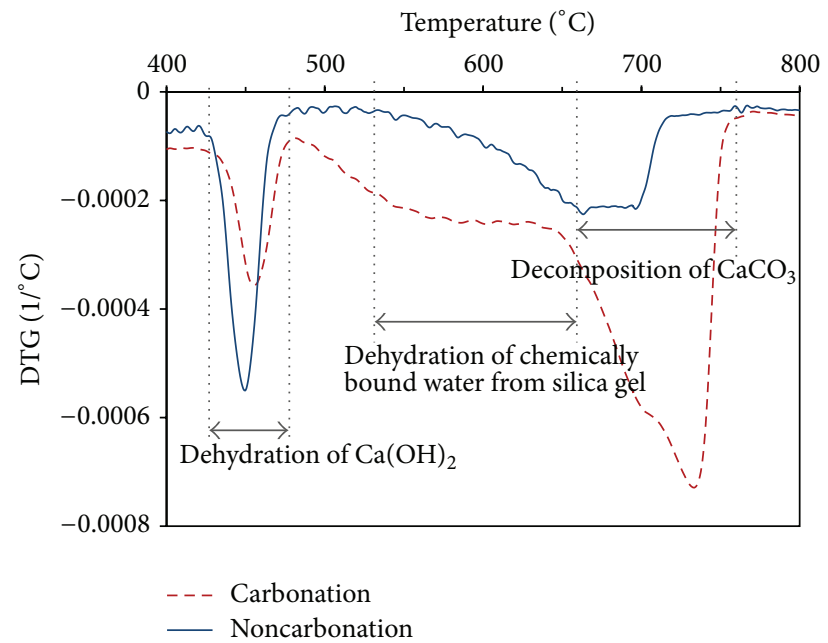

FIGURE 11: Differential thermograms (mass loss downwards) of noncarbonated and carbonated OPC mortar.

products, which appear to be shrinkage cracks created by high heat due to the large amount of added activator. When carbonation progressed, AAS showed significant disorganization and disintegration of its microstructure, unlike OPC. It was observed in the carbonated AAS that smooth and compact surfaces are disintegrated and separated or that some adhered to the surface, increasing the amount of porosity. This seems to have lowered the strength of AAS mortar after carbonation. However, the increasing addition of activator rather reduced the disintegration of the microstructure, most likely because the increase of $\mathrm{CSH}$ production by the activator strengthened the compaction of the microstructure.

\section{Conclusion}

The paper investigated the carbonation characteristics of AAS mortar. A series of experimental tests was performed to identify the change in the physical properties and products by carbonation in comparison with that of OPC. The following conclusions can be drawn from the current experimental results.

(1) OPC yields a variety of products, such as portlandite, $\mathrm{CSH}$, calcite, quartz, and silica gel, while AAS yields $\mathrm{CSH}$ in most cases with small amounts of aluminum compounds such as albite and sodium aluminium silica.

(2) Unlike OPC, AAS produces no portlandite and has a vulnerable $\mathrm{CSH}$ structure such that it shows relatively fast carbonation compared to OPC, which leads to a decrease in strength from the disintegration of the microstructure after carbonation.

(3) In AAS paste, CSH changes into amorphous silica gel. The microstructures of aluminum compounds such 


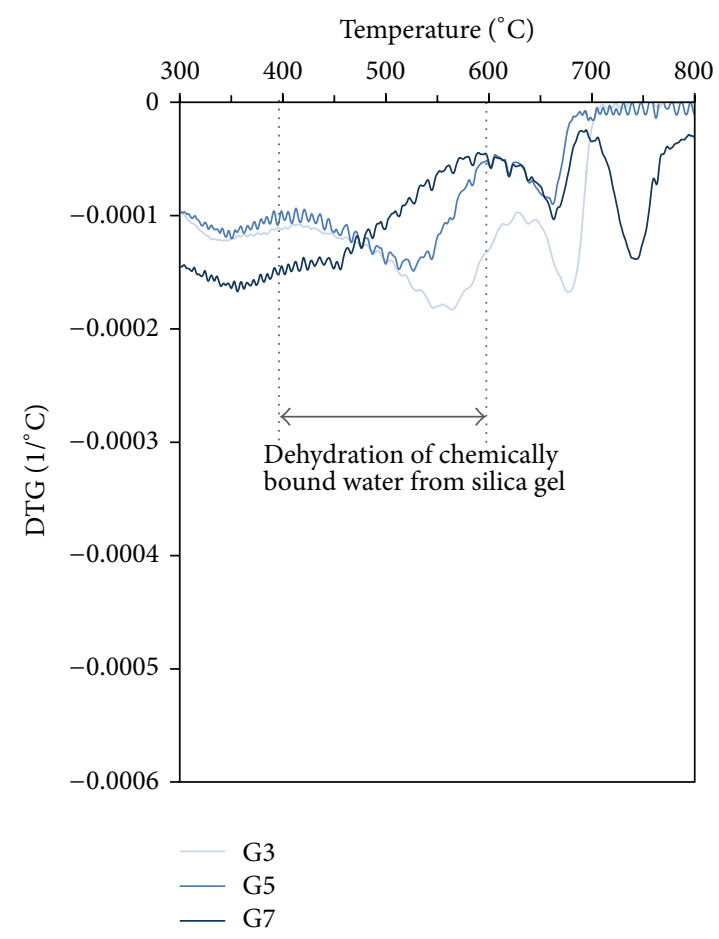

(a)

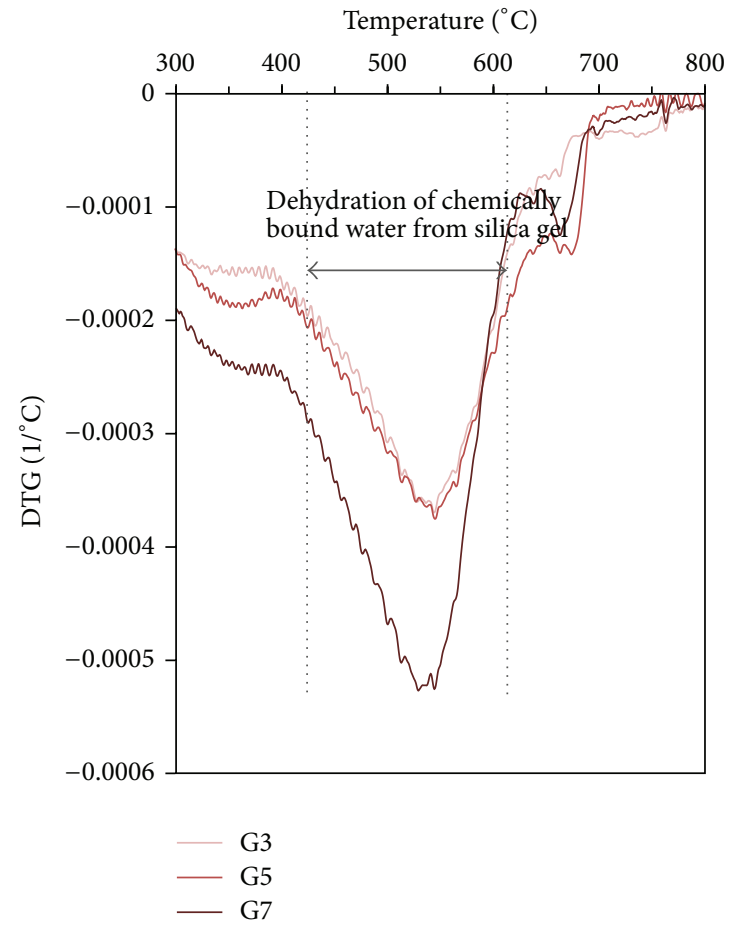

(b)

FIGURE 12: Differential thermograms (mass loss downwards) of noncarbonated (a) and carbonated (b) AAS mortar with different $\mathrm{Na}_{2} \mathrm{O} / \mathrm{S}$.M ratios.
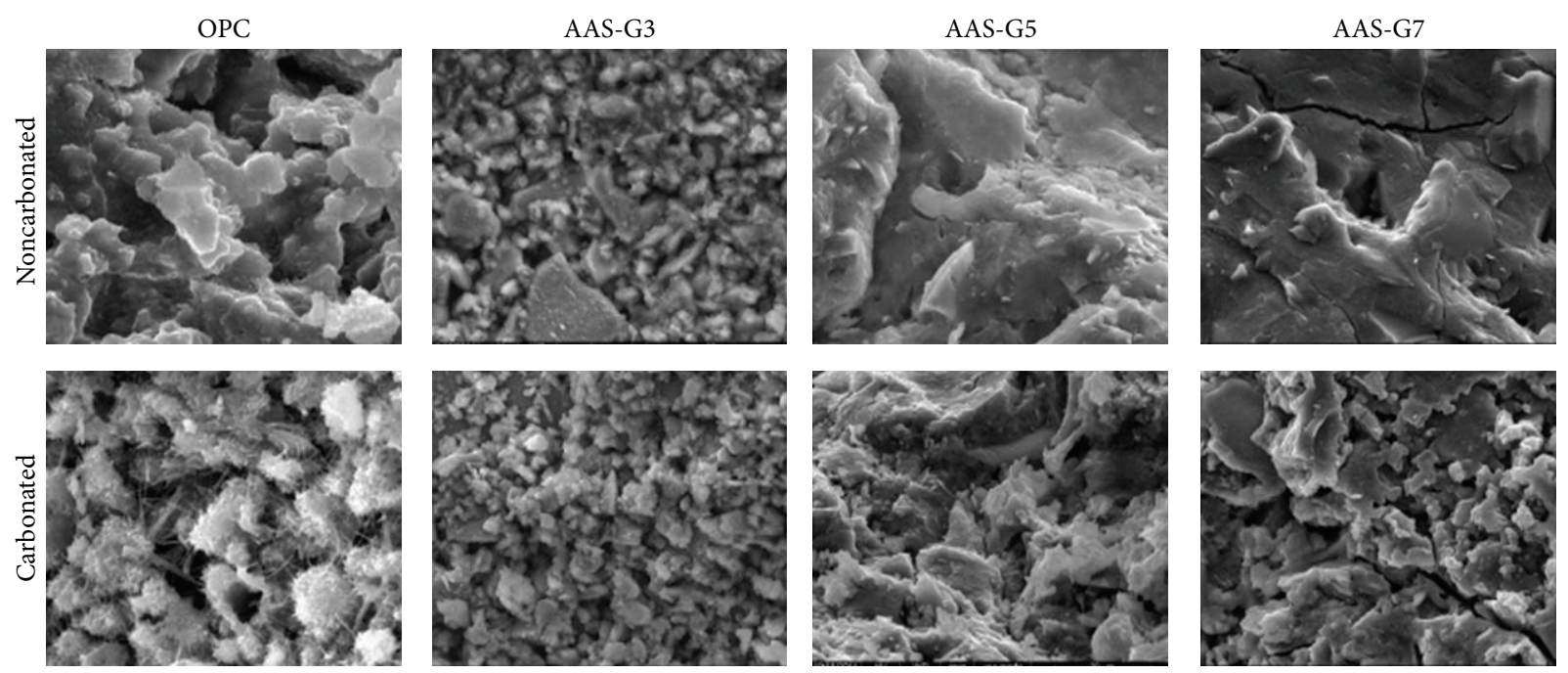

FIGURE 13: ESEM images $(\times 2,000)$ of noncarbonated and carbonated OPC and AAS mortar with different $\mathrm{Na}_{2} \mathrm{O} / \mathrm{S} . \mathrm{M}$ ratios.

as albite and sodium aluminium silica completely disintegrate with carbonation.

(4) The increasing addition of an activator to AAS accelerates the rate of reaction, creating more $\mathrm{CSH}$ per unit volume and increasing the compaction and strength of microstructure, which leads to high carbonation resistance and slow carbonation progress.

\section{Conflict of Interests}

The authors declare that there is no conflict of interests regarding the publication of this paper. 


\section{Acknowledgment}

This work was supported by the National Research Foundation of Korea (NRF) Grant funded by the Korean Government (MEST) (nos. 2011-0028983 and 2013R1A1A1006379).

\section{References}

[1] J. T. Houghton, B. A. Callander, and S. K. Varney, The Supplementary Report to the IPCC Scientific Assessment, Intergovernmental Panel on Climate Change, Cambridge University Press, Cambridge, UK, 1992.

[2] E. Gartner, "Industrially interesting approaches to low- $\mathrm{CO}_{2}$ cements," Cement and Concrete Research, vol. 34, no. 9, pp. 1489-1498, 2004.

[3] C. Meyer, "The greening of the concrete industry," Cement and Concrete Composites, vol. 31, no. 8, pp. 601-605, 2009.

[4] J. S. Damtoft, J. Lukasik, D. Herfort, D. Sorrentino, and E. M. Gartner, "Sustainable development and climate change initiatives," Cement and Concrete Research, vol. 38, no. 2, pp. 115127, 2008.

[5] K. Yang, J. Song, A. F. Ashour, and E. Lee, "Properties of cementless mortars activated by sodium silicate," Construction and Building Materials, vol. 22, no. 9, pp. 1981-1989, 2008.

[6] K. H. Yang, J. K. Song, K. S. Lee, and A. F. Ashour, "Flow and compressive strength of alkali-activated mortars," ACI Materials Journal, vol. 106, no. 7, pp. 50-58, 2009.

[7] K.-H. Yang and J.-K. Song, "Workability loss and compressive strength development of cementless mortars activated by combination of sodium silicate and sodium hydroxide," Journal of Materials in Civil Engineering, vol. 21, no. 3, pp. 119-127, 2009.

[8] T. Bakharev, Alkali Activated Slag Concrete: Chemistry, Microstructure and Durability [Ph.D. thesis], Monash University, Melbourne, Australia, 2006.

[9] S. D. Wang, K. L. Scrivener, and P. L. Pratt, "Factors affecting the strength of alkali-activated slag," Cement and Concrete Research, vol. 24, no. 6, pp. 1033-1043, 1994.

[10] J. I. Escalante-García, A. F. Fuentes, A. Gorokhovsky, P. E. Fraire-Luna, and G. Mendoza-Suarez, "Hydration products and reactivity of blast-furnace slag activated by various alkalis," Journal of the American Ceramic Society, vol. 86, no. 12, pp. 2148-2153, 2003.

[11] C. Shi, "Strength, pore structure and permeability of alkaliactivated slag mortars," Cement and Concrete Research, vol. 26, no. 12, pp. 1789-1799, 1996.

[12] C. Shi, "Corrosion resistance of alkali-activated slag cement," Advances in Cement Research, vol. 15, no. 2, pp. 77-81, 2003.

[13] T. Hakkinen, "Properties of alkali-activated slag concrete," VTT Research Notes 540, Technical Research Centre of Finland, 1986.

[14] P. D. Krivenko, "Alkaline cements," in Proceedings of the the 1st International Conference on Alkaline Cements and Concrete, Kiev, Ukraine, 1994.

[15] A. A. Adam, Strength and durability properties of alkali activated slag and fly ash-based geopolymer concrete [Ph.D. thesis], RMIT University, Melbourne, Australi, 2009.

[16] J. Malolepszy and J. Deja, "Durability of alkali activated slag mortars and concrete," in Proceedings of the 2nd International Conference on Alkaline Cements and Concretes, Krivenko, Ed., pp. 685-697, Kiev, Ukraine, 1999.
[17] T. Bakharev, J. G. Sanjayan, and Y. B. Cheng, "Resistance of alkali-activated slag concrete to carbonation," Cement and Concrete Research, vol. 31, no. 9, pp. 1277-1283, 2001.

[18] K. Byfors, E. Klingstedt, V. Lehtonene, H. Pyy, and L. Romben, "Durability of concrete made with alkali-activated slag," in Proceedings of the 3rd International Conference on the Use of Natural Pozzolans, Fly Ash, Blast Furnace Slag and Silica Fume in Concrete, ACI SP-114, pp. 1429-1466, 1989.

[19] V. D. Glukhovsky, G. S. Rostovkaya, and G. V. Rumyna, "High strength slag-alkali cement," in Proceedings of the 7th International Congress on the Chemistry of Cement, Paris, France, 1980.

[20] V. G. Papadakis, C. G. Vayenas, and M. N. Fardis, "Fundamental modeling and experimental investigation of concrete carbonation," ACI Materials Journal, vol. 88, no. 4, pp. 363-373, 1991.

[21] RILEM Committee CPC18, "Measurement for Hardened Concrete Carbonated Depth," TC14-CPC, 1988.

[22] R. J. Errington, Advanced Practical Inorganic and Metal Organic Chemistry, Chapman \& Hall, 1997.

[23] C. Chang and J. Chen, "The experimental investigation of concrete carbonation depth," Cement and Concrete Research, vol. 36, no. 9, pp. 1760-1767, 2006.

[24] F. Puertas, M. Palacios, and T. Vázquez, "Carbonation process of alkali-activated slag mortars," Journal of Materials Science, vol. 41, no. 10, pp. 3071-3082, 2006.

[25] S. A. Bernal, R. M. de Gutierrez, J. L. Provis, and V. Rose, "Effect of silicate modulus and metakaolin incorporation on the carbonation of alkali silicate-activated slags," Cement and Concrete Research, vol. 40, no. 6, pp. 898-907, 2010.

[26] S. A. Bernal, E. D. Rodriguez, R. M. Gutierrez, J. L. Provis, and S. Delvasto, "Activation of metakaolin/slag blends using alkaline solutions based on chemically modified silica fume and rice husk ash," Waste and Biomass Valorization, vol. 3, no. 1, pp. 99108, 2012.

[27] A. Fernández-Jiménez, F. Puertas, I. Sobrados, and J. Sanz, "Structure of calcium silicate hydrates formed in alkalineactivated slag: influence of the type of alkaline activator," Journal of the American Ceramic Society, vol. 86, no. 8, pp. 1389-1394, 2003.

[28] G.-F. Peng and Z.-S. Huang, "Change in microstructure of hardened cement paste subjected to elevated temperatures," Construction and Building Materials, vol. 22, no. 4, pp. 593-599, 2008. 

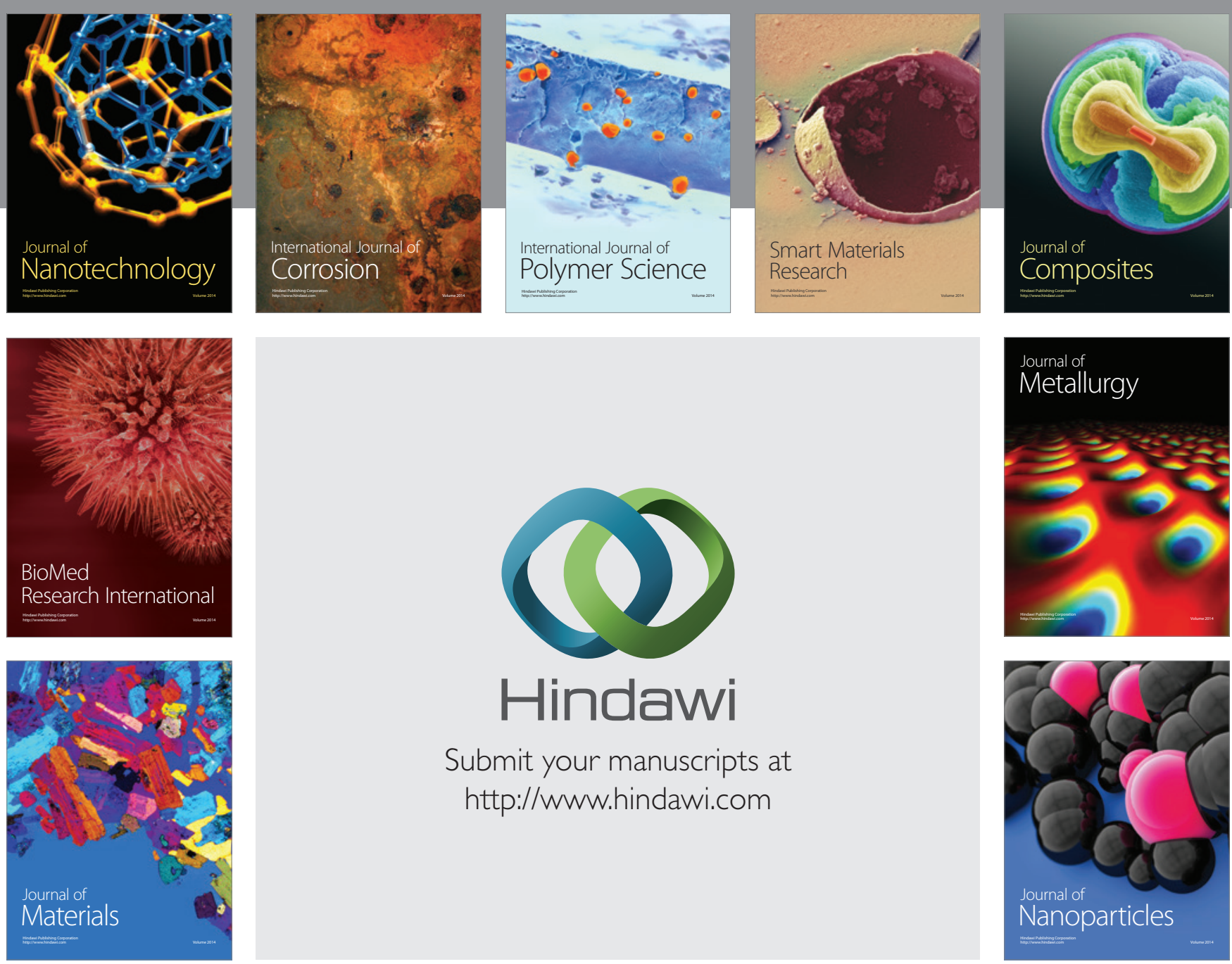

Submit your manuscripts at http://www.hindawi.com
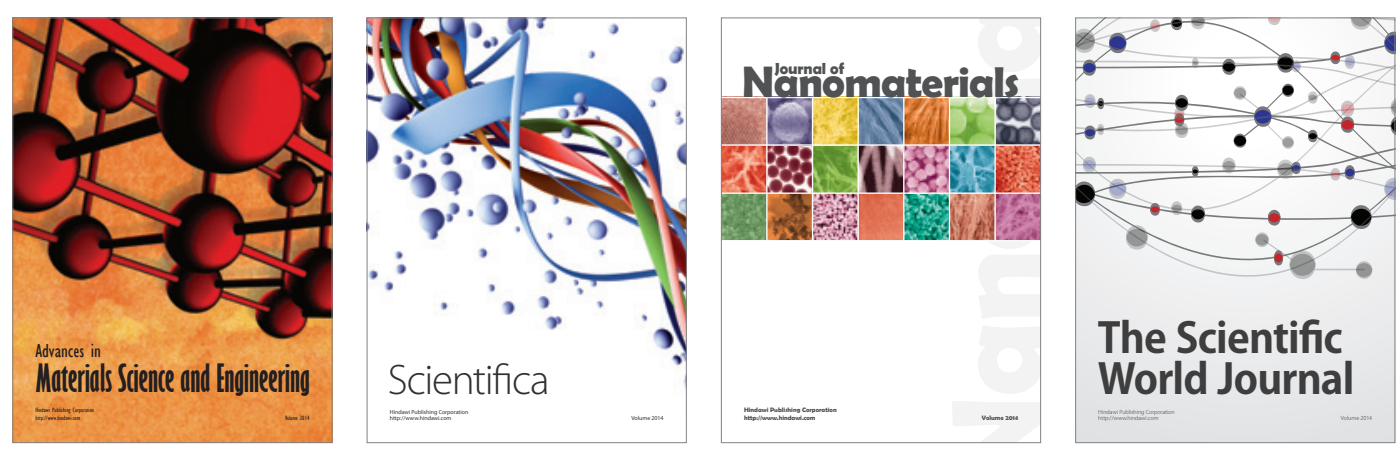

\section{The Scientific World Journal}
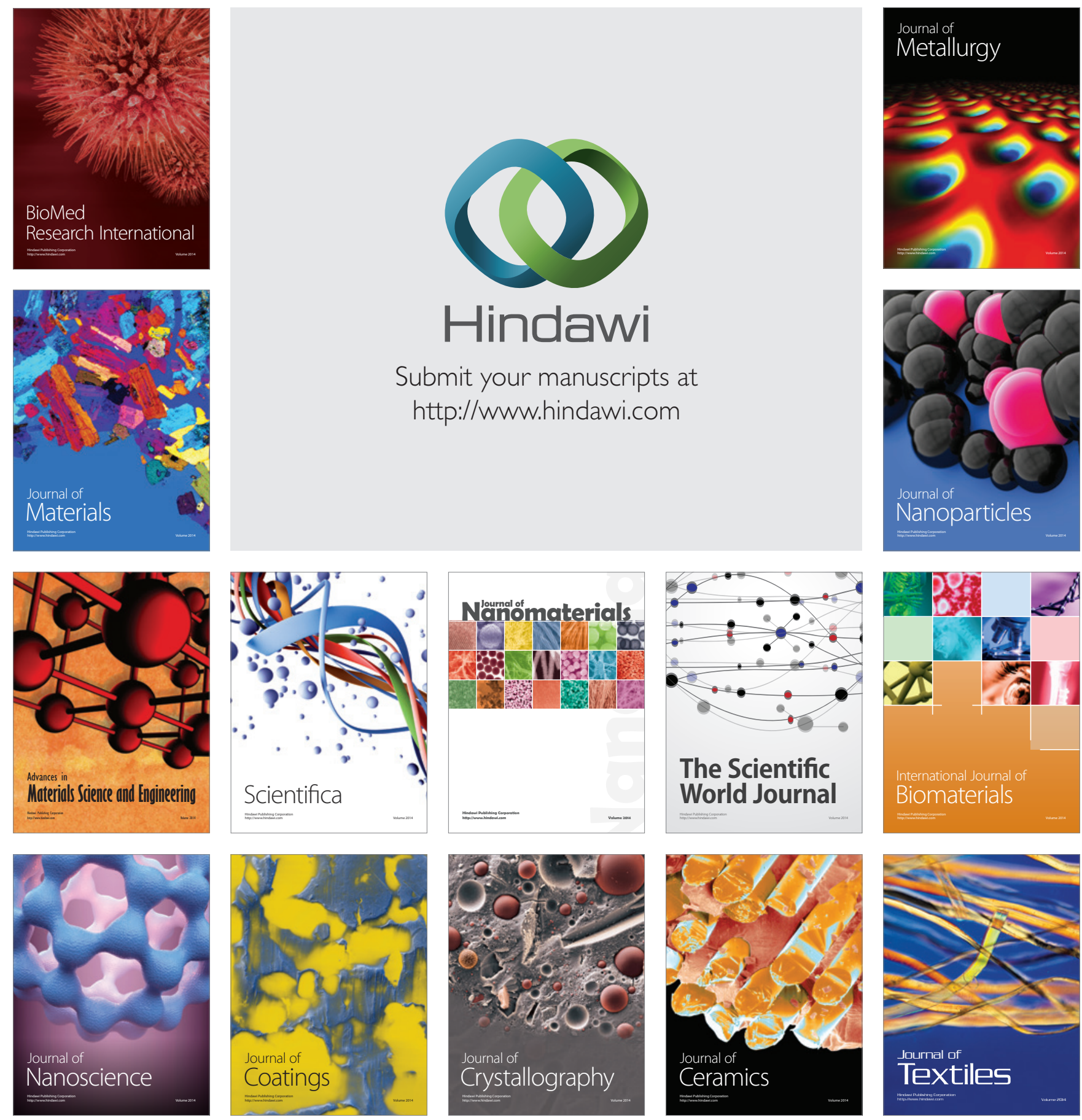